\title{
Tuning Nitric Oxide Adsorption in Cobalt-Triazolate Frameworks
}

\author{
Julia Oktawiec,a Henry Z. H. Jiang,a Ari B. Turkiewicz,a and Jeffrey R. Longa,b,c * \\ a Department of Chemistry, University of California, Berkeley, California 94720, USA. E-mail: jrlong@berkeley.edu \\ b Department of Chemical and Biomolecular Engineering, University of California, Berkeley, California 94720, USA \\ c Materials Sciences Division, Lawrence Berkeley National Laboratory, Berkeley, California, 94720, USA
}

\begin{abstract}
Nitric oxide (NO) is an important signaling molecule in biological systems, and as such the ability of certain porous materials to reversibly adsorb NO is of interest for medical applications. Metal-organic frameworks have been explored for their ability to reversibly bind NO at coordinatively-unsaturated metal sites, however the influence of metal coordination environment on NO adsorption has yet to be studied in detail. Here, we examine $\mathrm{NO}$ adsorption in the frameworks $\mathrm{Co}_{2} \mathrm{Cl}_{2}(\mathrm{bbta})$ and $\mathrm{Co} 2(\mathrm{OH})_{2}(\mathrm{bbta})$ $\left(\mathrm{H}_{2}\right.$ bbta $=1 H, 5 H$-benzo(1,2-d:4,5- $\left.d^{\prime}\right)$ bistriazole $)$ via gas adsorption, infrared spectroscopy, powder X-ray diffaction, and magnetometry measurements. While $\mathrm{NO}$ adsorbs reversibly in $\mathrm{Co}_{2} \mathrm{Cl}_{2}$ (bbta) without electron-transfer, adsorption of low pressures of $\mathrm{NO}$ in $\mathrm{Co}_{2}(\mathrm{OH})_{2}$ (bbta) is accompanied by charge transfer from the cobalt(II) centers to form a cobalt(III)-NOadduct, as supported by diffraction and infrared spectroscopy data. At higher pressures of NO, characterization data support additional uptake of the gas and disproportionation of the bound $\mathrm{NO}$ to form a cobalt(III)-nitro ( $\left.\mathrm{NO}_{2-}\right)$ species and $\mathrm{N}_{2} \mathrm{O}$ gas, a transformation that appears to be facilitated in part by stabilizing hydrogen bonding interactions between the bound $\mathrm{NO}_{2-}$ and framework hydroxo groups. This reactivity represents a rare example of reductive NO-binding in a metal-organic framework and demonstrates that NO binding can be tuned by changing the coordination environment of the framework metal centers.
\end{abstract}

\section{Introduction}

Nitric oxide (NO) is recognized as a key gasotransmitter with a number of important physiological roles, including as the endothelium-derived relaxing factor and as a neurotransmitter involved in memory formation and stroke damage. ${ }^{1,2}$ Given its influence on vasodilation, administration of $\mathrm{NO}$ gas and NO donor drugs is an important therapeutic strategy, and NO gas administration is under investigation as a potential supportive treatment for coronaviruses, in particular SARS-CoV-2. ${ }^{3-6}$ The reactivity of NO with proteins containing metal cofactors is critical to the therapeutic effects of this gas. ${ }^{7-10}$ For example, metal-heme proteins including guanylate cyclase, ${ }^{11}$ cytochrome $c$ oxidase, ${ }^{12}$ haemoglobin, ${ }^{13,14}$ and cobalamin ${ }^{15-18}$ bind nitric oxide at the metal site, an event that can either enable or interfere with critical metabolic pathways. In such metalloproteins, nitric oxide binding is facilitated by the low reduction potentials of the transition metal-containing cofactors, which facilitate NO binding via an electron-transfer mechanism to generate an oxidized metal and reduced NO adduct. ${ }^{7,14,19-21}$ However, because of the deleterious reactions that can occur in the presence of excess nitric oxide, careful and controlled delivery is an active area of research. ${ }^{22}$

Porous solid-state materials have generated considerable interest as NO-releasing therapeutics due to their tunability and high surface areas, and metal-organic frameworks a key class of materials under investigation. ${ }^{22-24}$ Composed of metal ion or cluster nodes and multitopic organic linkers, metal-organic frameworks display high degrees of thermal and chemical stability in addition to considerable chemical and structural variability. ${ }^{25,26}$ Adsorption of NO has been reported in a number of frameworks, including $\mathrm{Cu}_{3}(\mathrm{btc})_{2}$ (HKUST-1; btc ${ }^{3-}=1,3,5-$ benzenetricarboxylate), $\mathrm{M}_{2}$ (dobdc) $(\mathrm{M}=\mathrm{Mg}, \mathrm{Co}, \mathrm{Ni}$, and $\mathrm{Zn}$; dobdc $^{4-}=$ 2,5-dioxido-1,4-benzenedicarboxylate), and $\mathrm{Zr}_{6} \mathrm{O}_{4}(\mathrm{OH})_{4}(\mathrm{bdc})_{6} \quad\left(\mathrm{UiO}-66 ; \quad \mathrm{bdc}^{2-} \quad=\quad 1,4-\right.$ benzenedicarboxylate). ${ }^{27-29}$ Many of these materials physisorb NO at coordinatively-unsaturated metal centers, with little evidence of charge transfer. However, reduction of nitric oxide upon adsorption has been characterized in iron(II)-containing frameworks, such as $\mathrm{Fe}_{2}$ (dobdc) ${ }^{30} \mathrm{Fe}_{3} \mathrm{OX}(\mathrm{L})(\mathrm{X}=\mathrm{F}, \mathrm{Cl}$, or $\mathrm{OH}$, $\mathrm{L}^{2-}=$ fumarate $),{ }^{27}$ and Fe-MOF-5 $\left(\left[\mathrm{Zn}_{3} \mathrm{FeO}(\mathrm{btc})_{3}\right]_{8}\right){ }^{31,32}$ In the case of the former two materials, the NO unit is formally retained upon adsorption and is released in the presence of humidity. In contrast, upon binding at the iron(II) sites in Fe-MOF-5, NO disproportionates to form $\mathrm{N}_{2} \mathrm{O}$ and $\mathrm{NO}_{2}{ }^{-}$species. ${ }^{31}$ Characteristic of most of these examples is that NO is bound exclusively via an electron transfer mechanism, in the absence of contributions from favorable non-covalent interactions.

Recently, we demonstrated that the framework $\mathrm{Co}_{2}(\mathrm{OH})_{2}$ (bbta) $\quad\left(\mathrm{H}_{2}\right.$ bbta $=1 \mathrm{H}, 5 \mathrm{H}$-benzo $(1,2-d: 4,5-$ $d^{\prime}$ )bistriazole; Fig. 1b) reversibly binds $\mathrm{O}_{2}$ via electron transfer to form a cobalt(III)-superoxo adduct that is stabilized by hydrogen bonding with the bridging hydroxo groups of the framework. ${ }^{33}$ In contrast, the related framework $\mathrm{Co}_{2} \mathrm{Cl}_{2}$ (bbta) 
a
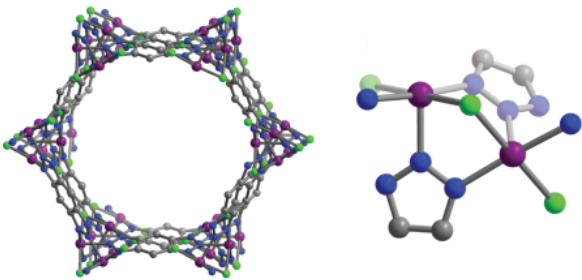

$\mathrm{Co}_{2} \mathrm{Cl}_{2}$ (bbta)
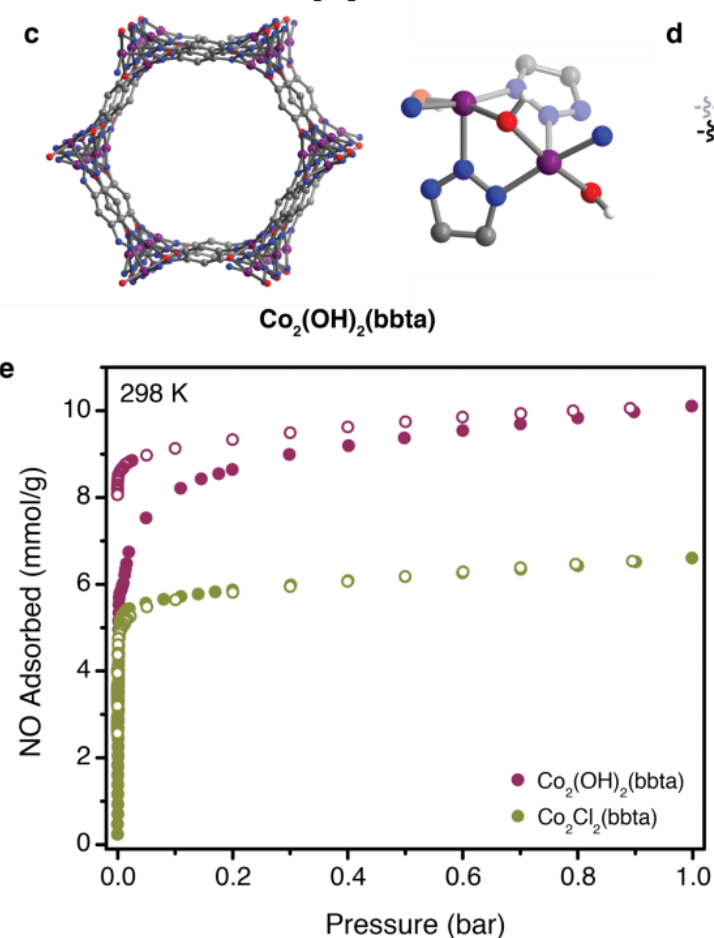

b

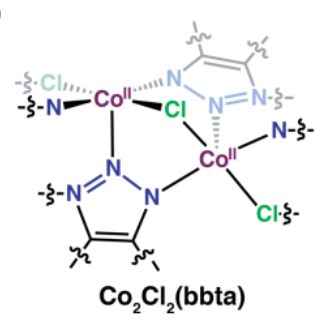<smiles></smiles>

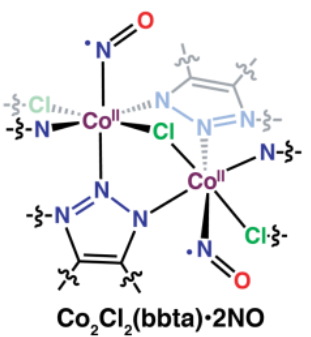

d

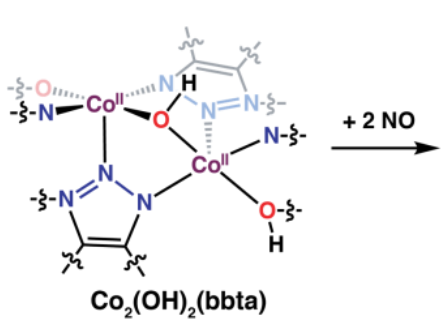

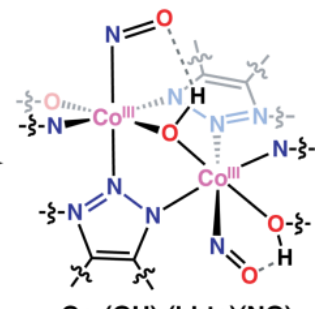

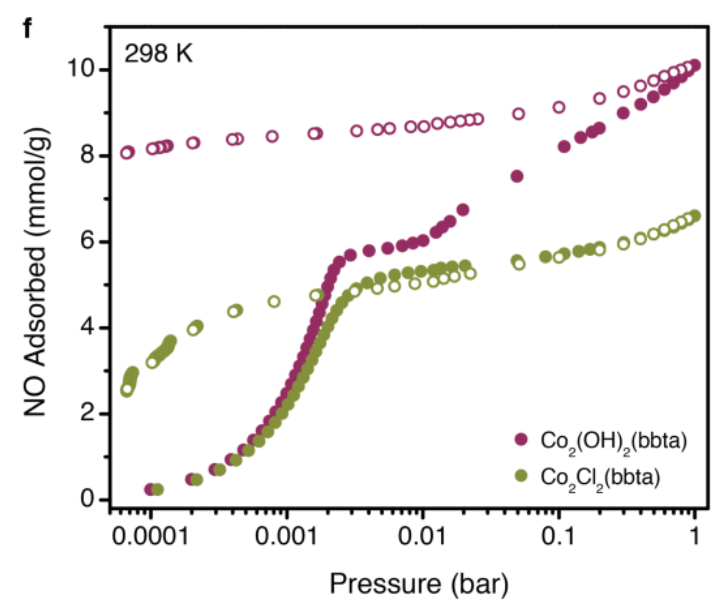

Fig. 1 Structures of $\mathrm{Co}_{2} \mathrm{Cl}_{2}$ (bbta) (a) and $\mathrm{Co}_{2}(\mathrm{OH})_{2}$ (bbta) (c), depicting the hexagonal framework pores and the local coordination environment of the cobalt centers in each material. Purple, red, blue, gray, and white spheres represent $\mathrm{Co}, \mathrm{O}, \mathrm{N}, \mathrm{C}$, and $\mathrm{H}$ atoms respectively. Scheme illustrating $\mathrm{NO}$ binding to the cobalt(II) centers of $\mathrm{Co} 2 \mathrm{Cl} 2$ (bbta) (b) and $\mathrm{CO}_{2}(\mathrm{OH})_{2}$ (bbta) (d). In the latter material, the more electron-rich cobalt centers reduce NO upon binding, generating cobalt(III)-NO adducts stabilized in part by a hydrogen bonding interactions with the framework bridging hydroxo groups, as indicated by spectroscopic and powder X-ray diffraction data. NO adsorption isotherms obtained for $\mathrm{Co}_{2} \mathrm{Cl}_{2}$ (bbta) (green symbols) and $\mathrm{Co}_{2}(\mathrm{OH})_{2}$ (bbta) (purple symbols) at $298 \mathrm{~K}$, with pressure presented on a linear (e) and logarithmic (f) scale. Closed and open circles represent adsorption and desorption points respectively.

(Fig. 1a) exhibits much weaker uptake of $\mathrm{O}_{2}$ with no associated electron transfer. Here, we demonstrate that synergistic electron transfer and stabilizing hydrogen bonding interactions can also promote strong binding of $\mathrm{NO}$ in $\mathrm{Co}_{2}(\mathrm{OH})_{2}$ (bbta) (Fig. 1b), and, at higher pressures, disproportionation of $\mathrm{NO}$ to yield a cobalt(III)-bound $\mathrm{NO}_{2}{ }^{-}$species. Additionally, the framework $\mathrm{Co}_{2} \mathrm{Cl}_{2}$ (bbta) is shown to exhibit strong and reversible adsorption of NO (Fig. 1d). The unique binding of NO in these frameworks is characterized by gas adsorption, infrared spectroscopy, powder X-ray diffraction, and magnetometry measurements.

\section{Results and Discussion}

The frameworks $\mathrm{Co}_{2}(\mathrm{OH})_{2}($ bbta $)$ and $\mathrm{Co}_{2} \mathrm{Cl}_{2}$ (bbta) have previously been studied as adsorbents for $\mathrm{O}_{2}{ }^{33,34}$ and $\mathrm{CO}_{2}{ }^{35}$ and have also demonstrated utility as electrocatalysts. ${ }^{36,37}$ In the case of $\mathrm{O}_{2}$, the strength of adsorption is dramatically enhanced when the framework bridging ligand is changed from chloride to hydroxide. ${ }^{33,34}$ This result is consistent with a more electron-rich ligand environment for the cobalt centers in $\mathrm{Co}_{2}(\mathrm{OH})_{2}(\mathrm{bbta})$ in comparison to those in $\mathrm{Co}_{2} \mathrm{Cl}_{2}$ (bbta), which enables them to more readily reduce oxygen. ${ }^{38}$ Because $\mathrm{NO}$, like $\mathrm{O}_{2}$, is capable of accepting an electron from transition metals, ${ }^{7}$ we sought to investigate how the electronic environment of the two frameworks may also give rise to distinct NO uptake behavior.

Notably, NO adsorption isotherms collected for both materials at $298 \mathrm{~K}$ exhibit an initial steep rise at low pressures, indicative of strong framework-gas interactions (Fig. 1e). At 0.1 bar, both materials adsorb approximately $92 \%$ of their theoretical capacity, assuming one molecule of NO per cobalt ion (5.30 and $6.02 \mathrm{mmol} / \mathrm{g}$ for $\mathrm{Co}_{2} \mathrm{Cl}_{2}$ (bbta) and $\mathrm{Co}_{2}(\mathrm{OH})_{2}$ (bbta) respectively; Fig. 1f). Interestingly, both frameworks exhibit a much higher affinity for $\mathrm{NO}$ than $\mathrm{O}_{2},{ }^{33}$ and the $\mathrm{NO}$ isotherm for $\mathrm{Co}_{2}(\mathrm{OH})_{2}$ (bbta) is only slightly steeper than that of $\mathrm{Co}_{2} \mathrm{Cl}_{2}$ (bbta) at low pressures. While the uptake of both frameworks begins to plateau above 120 mbar, the uptake of $\mathrm{Co}_{2}(\mathrm{OH})_{2}($ bbta $)$ rises again to achieve a capacity of $10.1 \mathrm{mmol} / \mathrm{g}(23.3 \mathrm{wt} \%)$ at $1 \mathrm{bar}$, one of the highest gravimetric capacities of any NO absorbent. 


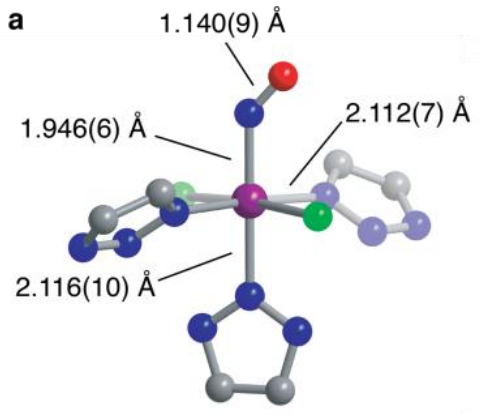

$\mathrm{Co}_{2} \mathrm{Cl}_{2}$ (bbta)-2NO b

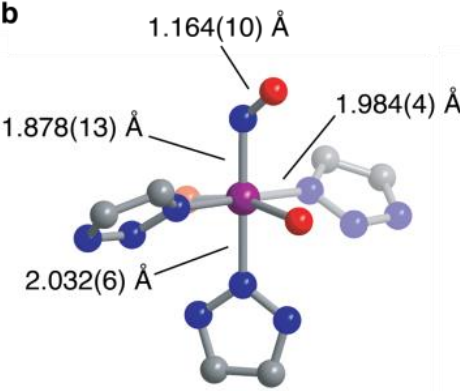

$\mathrm{Co}_{2}(\mathrm{OH})_{2}(\mathrm{bbta}) \cdot 1.82 \mathrm{NO}$ c

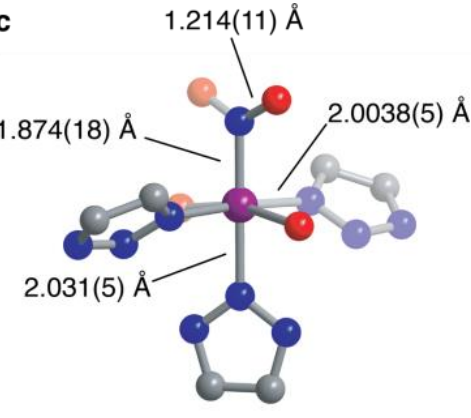

$\mathrm{Co}_{2}(\mathrm{OH})_{2}(\mathrm{bbta}) \cdot 1.88 \mathrm{NO}_{1.3}$

Fig. 2 Structural models determined from analysis of powder X-ray diffraction data for $\mathrm{Co}_{2} \mathrm{Cl}_{2}$ (bbta) dosed with 2 mbar $\mathrm{NO}$ gas (a) and $\mathrm{Co} 2(\mathrm{OH})_{2}(\mathrm{bbta})$ dosed with 2 mbar (b) and 200 mbar NO gas (c). Purple, red, blue, and gray spheres represent Co, O, N, and C atoms respectively; $\mathrm{H}$ atoms not shown as their positions could not be determined by Xrays. In (a) and (b) the occupancy of the represented oxygen atom position is half of that of the NO nitrogen atom, and the position of a second oxygen atom with the same degree of occupancy (generated by symmetry) is not shown for clarity. For the structure of $\mathrm{Co}_{2}(\mathrm{OH})_{2}(\mathrm{bbta})$ dosed with 200 mbar $\mathrm{NO}$, the occupancy of the $\mathrm{NO}$ oxygen atom increases to $60.8(16) \%$ of the NO nitrogen atom occupancy, nearly $15 \%$ more than would be expected for the structure with just bound NO and indicative of the presence of both bound $\mathrm{NO}$ and $\mathrm{NO}_{2-}$ species.

This capacity corresponds to an unexpected 1.57 equiv. of NO per cobalt center and is suggestive of additional reactivity beyond binding of $\mathrm{NO}$ to the metal sites of the framework. In contrast, the $\mathrm{NO}$ capacity of $\mathrm{Co}_{2} \mathrm{Cl}_{2}$ (bbta) is $6.6 \mathrm{mmol} / \mathrm{g}$ at $1 \mathrm{bar}$, which corresponds to 1.14 equiv. of $\mathrm{NO}$ gas per metal center. Interestingly, both frameworks also exhibit hysteresis upon desorption (Fig. 1f), although their recyclability of adsorption is drastically different: $\mathrm{Co}_{2} \mathrm{Cl}_{2}$ (bbta) retains $97.4 \%$ of its adsorption capacity over three adsorption/desorption cycles, while the capacity of $\mathrm{Co}_{2}(\mathrm{OH})_{2}$ (bbta) is greatly reduced after one cycle, even with attempted regeneration at temperatures up to $423 \mathrm{~K}$ (see the ESI and Figs. S1-S3 for details).

Nitric oxide uptake in both frameworks was further characterized by powder X-ray diffraction, infrared spectroscopy, and SQUID magnetometry. The powder X-ray diffraction pattern of $\mathrm{Co}_{2} \mathrm{Cl}_{2}$ (bbta) dosed with 2 mbar of $\mathrm{NO}$ gas features changes in unit cell parameters and peak intensities relative to the desolvated framework, indicative of structural changes upon NO adsorption (Fig. S11 and S12). Rietveld refinement yielded a structural model of NO-dosed $\mathrm{Co}_{2} \mathrm{Cl}_{2}$ (bbta) $\left(\mathrm{Co}_{2} \mathrm{Cl}_{2}\right.$ (bbta) $\left.2 \mathrm{NO}\right)$ wherein $\mathrm{NO}$ is bound in a bent, end-on fashion with a $\mathrm{Co}-\mathrm{N}-\mathrm{O}$ angle of $137.5(6)^{\circ}$, a $\mathrm{Co}-\mathrm{N}_{\mathrm{NO}}$ bond distance of 1.946(6) $\AA$, an N-O bond length of 1.140(9) $\AA$, similar to the bond length of free NO (1.154 $\AA$ ) (Fig. 2a). The unit cell volume of $\mathrm{Co}_{2} \mathrm{Cl}_{2}$ (bbta) decreases only slightly by 98.3 $\AA^{3}$ upon NO dosing, while the metal-ligand bonds remain the same as those in the bare material or increase slightly. For example, two $\mathrm{Co}-\mathrm{N}_{\text {triazolate }}$ bond distances increase from 2.064(10) and 2.106(6) $\AA$ in $\mathrm{Co}_{2} \mathrm{Cl}_{2}$ (bbta) to 2.112(7) and 2.116(10) $\AA$ in the NO-dosed framework, while the Co-Cl bond length increases from 2.377(3) to 2.3863(19) $\AA$. The decrease in in unit cell volume can be primarily attributed to a decrease in the $\mathrm{Cl}-\mathrm{Co}-\mathrm{Cl}$ bond angle from $179^{\circ}$ to $173^{\circ}$ and an increase in the $\mathrm{N}-\mathrm{Co}-\mathrm{N}$ bond angle from $175^{\circ}$ to $185^{\circ}$. Curiously, the structural changes upon NO binding do not appear to be related to changes in the cobalt oxidation or spin state, as the cobaltligand bond lengths of the framework remain consistent with those of high spin cobalt(II).
In contrast, dosing a sample of desolvated $\mathrm{Co}_{2}(\mathrm{OH})_{2}$ (bbta) with 2 mbar of $\mathrm{NO}$ gas at $298 \mathrm{~K}$ results in a drastic decrease in the framework unit cell volume, from 4427.7(3) to 4101.9(3) $\AA^{3}$. Rietveld refinement of the diffraction data (Figs. 2b and S13) revealed a structural model with the formula $\mathrm{CO}_{2}(\mathrm{OH})_{2}$ (bbta) $1.82 \mathrm{NO}$ featuring a bent $\mathrm{NO}$ over the cobalt centers of the framework. As a result of a two-fold axis running through the cobalt centers, the NO oxygen occupies two positions each with $45.7(5) \%$ occupancy. The structural parameters are indicative of the presence of cobalt(III)-nitrosyl species (Fig. 2b). ${ }^{7}$ Specifically, the $\mathrm{Co}-\mathrm{N}_{\text {triazole }}$ bond lengths decrease from 2.102(4) and 2.066(17) $\AA$ in the bare framework to 1.984(4) and 2.032(6) $\AA$ in the NO-dosed material, supporting a spin state change and/or charge transfer to generate cobalt(III). The slight elongation of the $\mathrm{N}-\mathrm{O}$ bond distance to 1.164(1) $\AA$, the $\mathrm{Co}-\mathrm{N}_{\mathrm{NO}}$ distance of $1.878(13) \AA$, and the $\mathrm{Co}-\mathrm{N}-\mathrm{O}$ angle of $129.3(8)^{\circ}$ are also consistent with those observed for other six coordinate $\{\mathrm{CoNO}\}^{8}$ systems. ${ }^{18,39}$ For example, characterization of nitroxylcobalamin derivatives via single-crystal X-ray diffraction revealed $\mathrm{Co}-\mathrm{N}_{\mathrm{NO}}$ bond lengths ranging from 1.907(2) to $1.940(8) \AA$ and $\mathrm{Co}-\mathrm{N}-\mathrm{O}$ angles ranging from $118.9(8)$ to $120.2(8)^{\circ} .{ }^{18} \mathrm{~A}$ lengthening of the metal-ligand bond trans to the $\mathrm{NO}$ is not observed for NO-dosed $\mathrm{Co}_{2}(\mathrm{OH})_{2}$ (bbta), despite the anticipated trans influence of $\mathrm{NO},{ }^{40}$ while in nitrosylcobalamin and $\mathrm{Fe}_{2}$ (dobdc) the trans ligand bond distance increases to more than $2.3 \AA . .^{18,30}$ The absence of such a perturbation in NO-dosed $\mathrm{Co}_{2}(\mathrm{OH})_{2}$ (bbta) might be due to an inability of the extended lattice of $\mathrm{Co}_{2}(\mathrm{OH})_{2}$ (bbta) to support large deviations in bond length. Finally, the oxygen of the NO moiety is resolved at a distance of 3.111(13) $\AA$ from the oxygen atom of the nearest bridging hydroxo group, close to that of the combined crystallographic van der Waals radii of two oxygen atoms (3.1 $\AA) .{ }^{41}$ This proximity indicates that hydrogen bonding may contribute to the adsorption of $\mathrm{NO}$ at low pressures, ${ }^{33,34,37}$ 

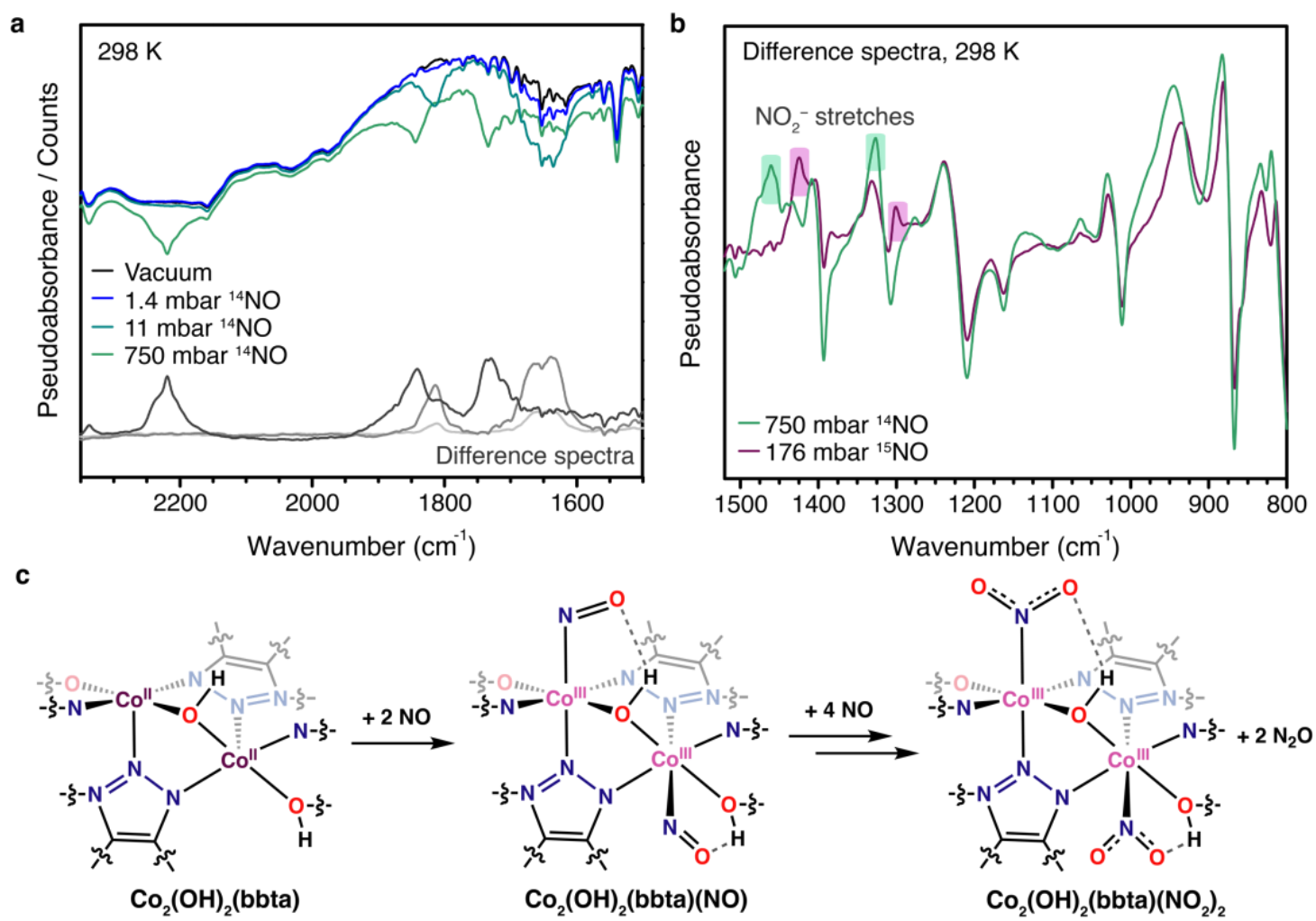

Fig. 3 (a) Raw DRIFTS spectra collected at $298 \mathrm{~K}$ for desolvated $\mathrm{Co} 2(\mathrm{OH})_{2}(\mathrm{bbta})$ under vacuum (black trace) and dosed with 1.4, 11 , and $750 \mathrm{mbar} 14 \mathrm{NO}$ gas (blue, teal, and green traces, respectively) between 2350 and $1500 \mathrm{~cm}-1$. This region features stretches that can be assigned to cobalt(III)- $\mathrm{NO}(1650-1840 \mathrm{~cm}-1)$ and $\mathrm{N}_{2} \mathrm{O}(2220 \mathrm{~cm}-1)$. The difference spectra relative to the desolvated framework for each gas pressure are shown at the bottom of the figure. (b) Difference spectra for $\mathrm{Co} 2(\mathrm{OH}) 2(\mathrm{bbta})$ dosed with $750 \mathrm{mbar} 14 \mathrm{NO}$ gas (green trace) and 176 mbar ${ }_{15} \mathrm{NO}$ gas (purple trace) relative to the desolvated framework under vacuum, between 800 and $1500 \mathrm{~cm}-1$. New bands at approximately 1460 and 1330 cm-1 in the spectrum for the ${ }_{14} \mathrm{NO}$-dosed sample and approximately 1424 and $1300 \mathrm{~cm}-1$ in the spectrum for the ${ }_{15} \mathrm{NO}$-dosed sample are highlighted in green and purple, respectively, and can be distinguished from the non-highlighted framework shifts, which are consistent in the presence of both gases. We note that the data for ${ }_{14} \mathrm{NO}$ and $15 \mathrm{NO}$ were collected using different pressures, which may account for the deviations in peak positions at lower wavenumbers. (c) Proposed scheme for $\mathrm{NO}$ uptake in $\mathrm{Co} 2(\mathrm{OH}) 2(\mathrm{bbta})$, which proceeds first through initial binding of 1 equiv. of NO per cobalt center to form a cobalt(III)-nitrosyl species (NO pressures up to at least 11 mbar) followed by subsequent disproportionation in the presence of additional NO at higher pressures ( 176 or 200 mbar as indicated by the infrared and diffraction data, respectively) to form a cobalt(III)-bound $\mathrm{NO}{ }_{2-}$ and gaseous $\mathrm{N}_{2} \mathrm{O}$

although the binding is likely primarily mediated by the strong interaction of the nitric oxide with the cobalt centers.

Powder X-ray diffraction data were also collected for $\mathrm{Co}_{2}(\mathrm{OH})_{2}$ (bbta) under 200 mbar $\mathrm{NO}$ to investigate the structural origins of the enhanced gas uptake at higher pressures in the adsorption isotherm (Fig. 2c and S14). Rietveld refinement of this data revealed a structural model wherein the occupancy factor of the NO oxygen is $60.8(16) \%$ of the NO nitrogen, an increase of approximately $15 \%$ from the 2 mbar structure. This change, in tandem with the elongation of the $\mathrm{N}-\mathrm{O}$ bond distance to $1.214(11) \AA$, suggests that the metal centers may be partially occupied by nitrite $\left(\mathrm{NO}_{2}^{-}\right)$as well as nitrosyl, due to $\mathrm{NO}$ disproportionation upon gas uptake at higher pressures. Interestingly, in this structure, the $\mathrm{NO}$ oxygen is also much closer to the framework hydroxo group than in the 2 mbar structure, with an $\mathrm{O}(\mathrm{H}) \cdots \mathrm{O}_{\mathrm{NO}}$ distance of $2.89(4) \AA$ and a smaller Co-N$\mathrm{O}$ angle of $117.6(9)^{\circ}$ (Fig. 2c). These structural differences further indicate that at higher NO pressures, hydrogen bonding might significantly stabilize the adsorbed species in $\mathrm{Co}_{2}(\mathrm{OH})_{2}$ (bbta).

In situ infrared spectra were collected for NO-dosed samples of both frameworks to further elucidate changes upon NO adsorption. In the case of $\mathrm{Co}_{2} \mathrm{Cl}_{2}$ (bbta), these data indicate that there is minimal electronic perturbation of the cobalt center upon NO binding, consistent with the diffraction data. For example, dosing with 1 mbar of NO gas results in the appearance of a peak at $1857 \mathrm{~cm}^{-1}$ that shifts gradually to $1841 \mathrm{~cm}^{-1}$ under increasing pressures of NO up to 1 bar (Figs. S7 and S8), energies that are only slightly shifted from the value for free NO $\left(1876 \mathrm{~cm}^{-1}\right)$. Additionally, the bands associated with framework vibrations do not shift significantly upon NO binding, signifying that adsorption does not substantially perturb the material. While it was not possible to heat the sample in the IR spectrometer to fully desorb the NO after dosing with 1 bar, evacuation at $298 \mathrm{~K}$ over the course of several hours resulted in a spectrum resembling that of the sample when dosed with 1 mbar of NO (Fig. S9), indicative of some degree of reversible adsorption.

Consistent with the gas adsorption and powder X-ray diffraction data, the infrared spectrum of $\mathrm{Co}_{2}(\mathrm{OH})_{2}(\mathrm{bbta})$ changes more dramatically upon dosing with $\mathrm{NO}$, indicative of an oxidation-state change in the material similar to what was characterized upon dosing the material with $\mathrm{O}_{2} \cdot{ }^{33} \mathrm{In}$ order to deconvolute bands arising due to NO adducts, infrared spectra were collected upon dosing with ${ }^{14} \mathrm{NO}$ (up to 750 mbar) and 
${ }^{15} \mathrm{NO}$ (up to 176 mbar) at $298 \mathrm{~K}$ (Figs. 3a,b and S6). Under 11 mbar of ${ }^{14} \mathrm{NO}$, two new broad features appear at 1814 and 1652 $\mathrm{cm}^{-1}$ and these shift to 1780 and $1624 \mathrm{~cm}^{-1}$, respectively, when the framework is dosed with the same pressure of ${ }^{15} \mathrm{NO}$ (Fig. S6). These features were assigned as the $v(\mathrm{NO})$ band of one or more cobalt(III)-NO ${ }^{-}$adducts. At a pressure of 750 mbar ${ }^{14} \mathrm{NO}$, these bands shift to lower energies of 1844 and $1730 \mathrm{~cm}^{-1}$, respectively, indicating further perturbation of the NO adduct. Additionally, at this higher pressure new bands appear at 1460 and $1326 \mathrm{~cm}^{-1}$ (1424 and $1300 \mathrm{~cm}^{-1}$, respectively, for the material dosed with 176 mbar ${ }^{15} \mathrm{NO}$ ), consistent with the asymmetric and symmetric $\mathrm{NO}$ stretch of an $\mathrm{NO}_{2}{ }^{-}$moiety bound to cobalt(III); ${ }^{42,43}$ another new peak at $2220 \mathrm{~cm}^{-1}$ corresponds to free $\mathrm{N}_{2} \mathrm{O}$ (Fig. $3 \mathrm{a}-\mathrm{c}$ ). ${ }^{44}$ Due to poor scattering at lower wavenumbers, it was not possible to observe the $\mathrm{NO}_{2}$ bend or Co-N stretch, which are predicted to appear at approximately 830 and $500 \mathrm{~cm}^{-1} \cdot{ }^{42,43,45} \mathrm{We}$ note that there is no distinct isotopically sensitive NO band between 1100 and $1050 \mathrm{~cm}^{-1}$, which would indicate the presence of a nitrito rather than a nitro moiety (i.e., $\mathrm{O}$ rather than $\mathrm{N}$-linkage) ${ }^{45}$ Notable changes also occur to the $v(\mathrm{OH})$ of the bridging hydroxo unit upon NO dosing: the band of the desolvated framework at $3647 \mathrm{~cm}^{-1}$ diminishes substantially upon dosing with NO pressures of 750 mbar $\left({ }^{14} \mathrm{NO}\right)$ or $176 \mathrm{mbar}\left({ }^{15} \mathrm{NO}\right)$, while a new group of bands appears at 3598 $\mathrm{cm}^{-1}$ under 11 mbar of ${ }^{14 / 15} \mathrm{NO}$. At the highest pressures examined for each gas, a second, even more redshifted band is present at $3517 \mathrm{~cm}^{-1}$ (Fig. S6), which was assigned to a hydrogen bond between the bridging hydroxo group and the adsorbed $\mathrm{NO}$ (or $\mathrm{NO}_{2}^{-}$) species

Dc magnetic susceptibility data were collected for $\mathrm{Co}_{2} \mathrm{Cl}_{2}$ (bbta), $\mathrm{Co}_{2}(\mathrm{OH})_{2}$ (bbta), and NO-dosed samples to further probe changes occurring upon NO binding in each material. In the case of $\mathrm{Co}_{2} \mathrm{Cl}_{2}$ (bbta), the room temperature molar magnetic susceptibility temperature product $\left(\chi_{\mathrm{M}} T\right.$, per formula unit) is 6.78 $\mathrm{emu} \cdot \mathrm{K} / \mathrm{mol}$ (3.39 $\mathrm{emu} \cdot \mathrm{K} / \mathrm{mol}$ per cobalt). This value decreases to $2.45 \mathrm{emu} \cdot \mathrm{K} / \mathrm{mol}$ per formula unit or $1.23 \mathrm{emu} \cdot \mathrm{K} / \mathrm{mol}$ per cobalt upon dosing with NO (Fig. 4a), close to that predicted for an antiferromagnetically coupled high spin $S=3 / 2$ cobalt(II) center and a $S=1 / 2$ NO molecule $(1 \mathrm{emu} \cdot \mathrm{K} / \mathrm{mol})$. The ambiguity in assigning oxidation states for NO-bound metal complexes complicates the interpretation of the magnetic data. ${ }^{39}$ However, taken in concert with the gas adsorption, powder X-ray diffraction, and infrared spectroscopy data, NO appears to undergo only a minor perturbation upon binding to the metal sites of $\mathrm{Co}_{2} \mathrm{Cl}_{2}$ (bbta), consistent with coupling but not electron transfer from cobalt to NO.

Dc magnetic susceptibility data collected for NO-dosed $\mathrm{Co}_{2}(\mathrm{OH})_{2}$ (bbta) are also distinct from data for the desolvated framework (Fig. 4b). Much like what was observed in the case of $\mathrm{Co}_{2} \mathrm{Cl}_{2}$ (bbta), there is a significant lowering of the $\chi_{\mathrm{M}} T$ product from $4.84 \mathrm{emu} \cdot \mathrm{K} / \mathrm{mol}$ in the desolvated material to 1.15 $\mathrm{emu} \cdot \mathrm{K} / \mathrm{mol}$ in the NO-dosed material $(2.42$ and 0.575 $\mathrm{emu} \cdot \mathrm{K} / \mathrm{mol}$ per cobalt). While the moment of the NO-dosed framework does not appear to have reached saturation even at room temperature, it is lower than the value predicted for either a coupled or uncoupled high spin $S=3 / 2$ cobalt(II) and an $S=1 / 2$ $\mathrm{NO}$ unit (1 and $2.25 \mathrm{emu} \cdot \mathrm{K} / \mathrm{mol}$, respectively) as well as that predicted for an $S=0$ cobalt(III) center and an $S=1 \mathrm{NO}^{-}$(1 $\mathrm{emu} \cdot \mathrm{K} / \mathrm{mol})$. In tandem with the clear shift of the $v(\mathrm{NO})$ and framework-based bands in the infrared spectroscopy data and the changes in structural parameters of both the framework and NO adduct in the powder $\mathrm{X}$-ray diffraction data, the magnetic data support the reduction of $\mathrm{NO}$ by $\mathrm{Co}_{2}(\mathrm{OH})_{2}$ (bbta) upon adsorption.

In all, the foregoing data reveal that adsorption of NO in $\mathrm{Co}_{2}(\mathrm{OH})_{2}$ (bbta) is accompanied by more drastic structural and electronic changes than in the case of $\mathrm{Co}_{2} \mathrm{Cl}_{2}$ (bbta). These changes are indicative of electron transfer from cobalt(II) to NO in $\mathrm{Co}_{2}(\mathrm{OH})_{2}$ (bbta) and are consistent with the more basic ligand set in this framework relative to $\mathrm{Co}_{2} \mathrm{Cl}_{2}$ (bbta), which can better stabilize the cobalt(III) oxidation state. ${ }^{46}$ Interestingly, as evidenced by infrared spectroscopy data at pressures above 176 mbar and diffraction data obtained at 200 mbar NO, charge transfer to adsorbed NO appears to further facilitate some degree

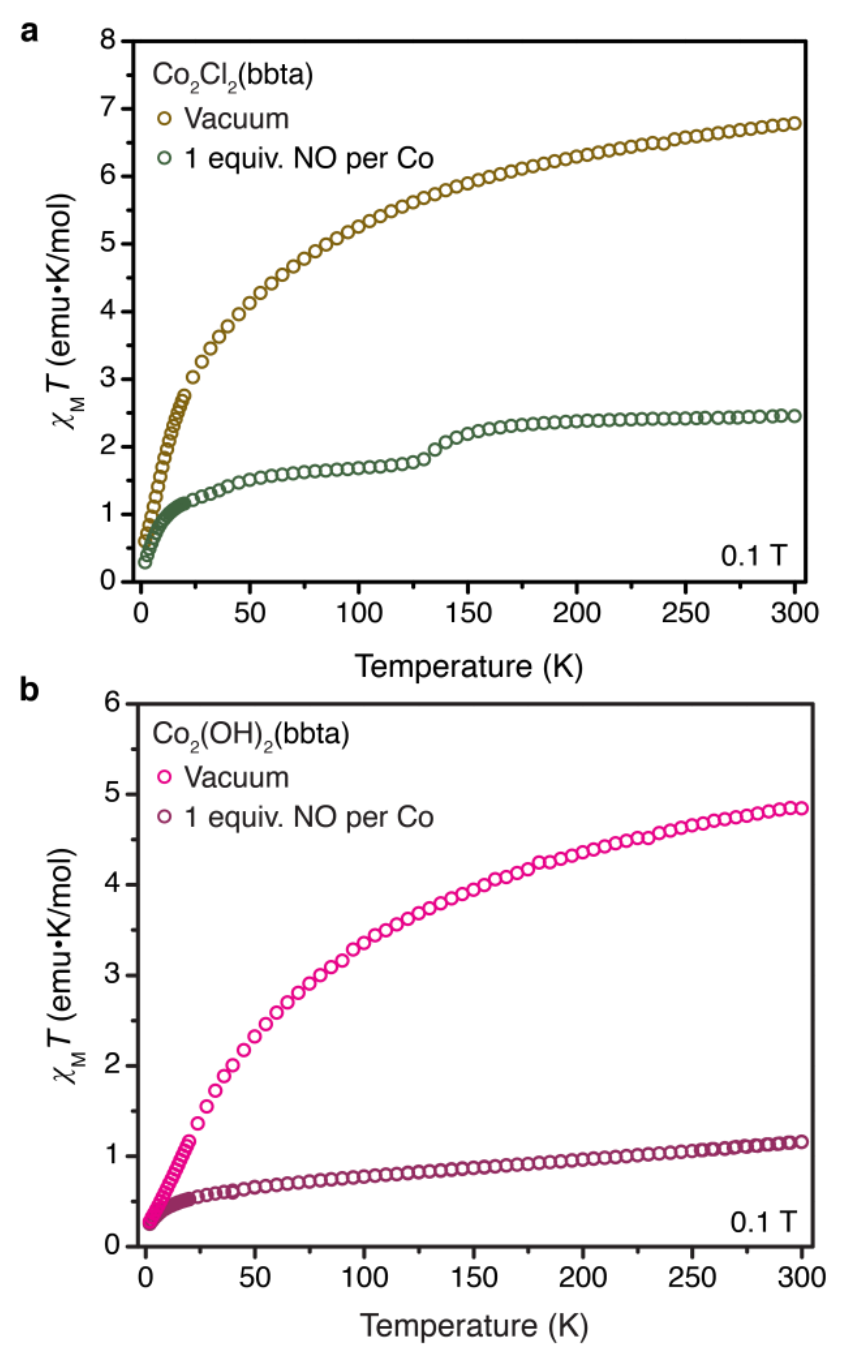

Fig. 4 (a) Plot of the molar magnetic susceptibility times temperature $(\chi \mathrm{M} T)$ versus $T$ for desolvated $\mathrm{Co}_{2} \mathrm{Cl}_{2}$ (bbta) (yellow-green symbols) and desolvated $\mathrm{Co}_{2} \mathrm{Cl}_{2}$ (bbta) dosed with 1 equiv. of NO per cobalt (green symbols). The slight dip in the data at 130 $\mathrm{K}$ corresponds to the boiling point of $\mathrm{NO}$ gas. (b) Plot of $\chi_{\mathrm{M} T} T$ versus $T$ for desolvated $\mathrm{Co} 2(\mathrm{OH})_{2}$ (bbta) (pink symbols) and desolvated $\mathrm{Co}_{2}(\mathrm{OH})_{2}$ (bbta) dosed with 1 equiv. of NO per cobalt (purple symbols). All data were collected under a dc field of $0.1 \mathrm{~T}$. Data for desolvated $\mathrm{Co}_{2} \mathrm{Cl}_{2}$ (bbta) and $\mathrm{Co}_{2}(\mathrm{OH})_{2}$ (bbta) are reproduced from ref. 33 . 
of disproportionation to form cobalt(III)-bound $\mathrm{NO}_{2}{ }^{-}$and $\mathrm{N}_{2} \mathrm{O}$ gas. In an isotherm measurement, the formed $\mathrm{N}_{2} \mathrm{O}$ is likely to desorb into the headspace of the sample holder such that, for a given pressure, the equivalency of $\mathrm{NO}$ as measured by the gas adsorption analyzer will appear less than the actual NO that is required to generate the corresponding proportion of cobalt(III)$\mathrm{NO}_{2}{ }^{-}$adducts. Taking this into account, if we assume that at 1 bar of NO the adsorbed species is exclusively $\mathrm{NO}_{2}^{-}$, a capacity of $10.1 \mathrm{mmol} / \mathrm{g}$ ( 1.57 equiv. NO per Co, Fig. 1e,f) would suggest as many as $78.5 \%$ of the cobalt sites have reacted with coordinated $\mathrm{NO}$ to form bound $\mathrm{NO}_{2}{ }^{-}$and gaseous $\mathrm{N}_{2} \mathrm{O}$, a similar level of oxidative reactivity to that observed previously with $\mathrm{O}_{2}{ }^{33}$

The occurrence of a disproportionation reaction at higher NO pressures also explains why $\mathrm{Co}_{2}(\mathrm{OH})_{2}$ (bbta) cannot be fully regenerated after NO uptake at pressures beyond a few hundred mbar. Indeed, attempted regeneration of a sample of $\mathrm{Co}_{2}(\mathrm{OH})_{2}$ (bbta) following isotherm data collection yielded a crystalline solid with a powder $\mathrm{X}$-ray diffraction pattern distinct from that of desolvated $\mathrm{Co}_{2}(\mathrm{OH})_{2}$ (bbta) (Fig. S15). In particular, the resulting unit cell volume is smaller than that of the parent desolvated material, which indicates that the material remains partially oxidized, as would be expected upon formation of cobalt(III)-bound $\mathrm{NO}_{2}^{-}$and $\mathrm{N}_{2} \mathrm{O}$ gas. While a satisfactory Rietveld refinement could not be performed, Fourier difference maps suggest residual electron density over the metal centers and near the hydroxo group. This data is suggestive of bound $\mathrm{NO}_{2}{ }^{-}$ species that would likely display strong interactions with the bridging hydroxo groups. Additionally, these differences are consistent with those observed in the infrared spectra of the framework upon NO dosing at high pressures, such as the generation of a cobalt(III)-nitro species and dramatic shifts in the hydroxo group bands. Indeed, hydrogen bonding likely plays an important role in facilitating NO disproportionation, much like other examples of nearby Lewis acids and hydrogen bond donors aiding in transition metal complex reactivity with NO. ${ }^{47-}$ ${ }^{49}$ In particular, the hydrogen bond may help to further polarize the NO adduct, promoting its reaction with additional equivalents of nitric oxide to form nitrous oxide.

\section{Conclusions}

The foregoing results demonstrate that both $\mathrm{Co}_{2} \mathrm{Cl}_{2}$ (bbta) and $\mathrm{Co}_{2}(\mathrm{OH})_{2}$ (bbta) are capable of strongly binding $\mathrm{NO}$, and notably these materials constitute only the second and third example of cobalt-based metal-organic frameworks for NO capture. $\mathrm{Co}_{2} \mathrm{Cl}_{2}$ (bbta) displays reversible nitric oxide binding and a high adsorption capacity at room temperature, making it a promising material for nitric oxide delivery. We note that while data on the toxicity of $\mathrm{Co}_{2} \mathrm{Cl}_{2}$ (bbta) and $\mathrm{Co}_{2}(\mathrm{OH})_{2}$ (bbta) are unavailable, one study that examined the effects of a wide range of metal-organic frameworks in human cell lines and zebrafish embryo found that the cobalt-based framework $\mathrm{Co}_{2}$ (dobdc) showed minimal toxicity in vitro and in vivo, and that health effects of frameworks in vitro and in vivo appeared to be related to metal ion identity. ${ }^{50}$ These results suggest that $\mathrm{Co}_{2} \mathrm{Cl}_{2}$ (bbta) might be similarly benign.
The introduction of a more basic bridging hydroxo ligand in the material $\mathrm{Co}_{2}(\mathrm{OH})_{2}$ (bbta) promotes charge transfer from cobalt(II) to NO, and at higher pressures $(>0.1$ bar) of $\mathrm{NO}$, disproportionation is clearly favored, with formation of $\mathrm{N}_{2} \mathrm{O}$ and generation of cobalt(III)-nitro species, as observed by in situ infrared spectroscopy. Additionally, powder X-ray diffraction and spectroscopic data indicate that the hydroxo moiety of the framework engages in hydrogen bonding to the adsorbed NO, which may promote the observed disproportionation reactivity at higher pressures. As in the case of Fe-MOF-5, the infrared spectra for $\mathrm{Co}_{2}(\mathrm{OH})_{2}$ (bbta) obtained at different $\mathrm{NO}$ pressures indicate the presence of adsorbed intermediates and more than one type of reduced product, which could not be definitively assigned. However, it is anticipated that further study of NO adsorption in this material at lower temperatures, as well as computational validation, could elucidate the identities of these intermediates, allowing for the determination of the mechanism of NO disproportionation in this framework. This knowledge would be useful for tuning and controlling denitrification reactions in metal-organic frameworks, ${ }^{51}$ and future studies could contribute critical insights in this regard. ${ }^{21,52-55}$

\section{Conflicts of interest}

There are no conflicts to declare.

\section{Acknowledgements}

We thank the U.S. Department of Energy Office of Basic Energy Sciences (DE-SC0019992) for support for experimental work, as well as the National Science Foundation for graduate fellowship support of J.O. and A.B.T. Powder X-ray diffraction data were collected on Beamline 17-BM-B at the Advanced Photon Source, a U.S. Department of Energy Office of Science User Facility operated by Argonne National Laboratory, supported by the U.S. Department of Energy Office of Basic Energy Sciences (DE-AC02-06CH11357). We additionally thank Dr. Andrey Yakovenko, Dr. Wenqian Xu, Dr. Benjamin Trump, and Maria Paley for assistance with powder X-ray diffraction measurements and Dr. Katie Meihaus for editorial assistance.

\section{References}

$1 \quad$ E. Culotta and D. E. Koshland, Science, 1992, 258, 18611865.

2 L. J. Ignarro, G. M. Buga, K. S. Wood, R. E. Byrns and G. Chaudhuri, Proc. Natl. Acad. Sci. U. S. A., 1987, 84, 92659269.

3 M. R. Miller and I. L. Megson, Br. J. Pharmacol., 2007, 151, 305-321.

4 J. Martel, Y.-F. Ko, J. D. Young and D. M. Ojcius, Microbes Infect., 2020, 22, 168-171.

5 L. Chen, P. Liu, H. Gao, B. Sun, D. Chao, F. Wang, Y. Zhu, G. Hedenstierna and C. G. Wang, Clin. Infect. Dis., 2004, 39, 1531-1535.

6 S. Åkerström, V. Gunalan, C. T. Keng, Y. J. Tan and A. 
Mirazimi, Virology, 2009, 395, 1-9. 1155-1165. Rev., 2010, 62, 525-563. 1504, 46-57. Biochemistry, 1987, 26, 3837-3843. 401-417. 2010, 49, 6260-6266.

Elsevier, 2019, pp. 277-305. 330-334. 5, 1701043. 112, 673-674.
J. A. McCleverty, Chem. Rev., 2004, 104, 403-418.

J. A. McCleverty, Chem. Rev., 1979, 79, 53-76.

A. R. Butler and I. L. Megson, Chem. Rev., 2002, 102,

R. Radi, Chem. Res. Toxicol., 1996, 9, 828-835.

S. H. Francis, J. L. Busch and J. D. Corbin, Pharmacol.

G. C. Brown, Biochim. Biophys. Acta - Bioenerg., 2001,

R. Gardiner, T. G. Traylor, V. S. Sharma and H. Mizukami,

J. F. Deatherage and K. Moffat, J. Mol. Biol., 1979, 134,

M. Brouwer, W. Chamulitrat, G. Ferruzzi, D. L. Sauls and J. B. Weinberg, Blood, 1996, 88, 1857-1864.

L. Hannibal, C. A. Smith, D. W. Jacobsen and N. E. Brasch, Angew. Chemie - Int. Ed., 2007, 46, 5140-5143.

M. Wolak, A. Zahl, T. Schneppensieper, G. Stochel and R. Van Eldik, J. Am. Chem. Soc., 2001, 123, 9780-9791.

H. A. Hassanin, M. F. El-Shahat, S. DeBeer, C. A. Smith and N. E. Brasch, Dalton Trans., 2010, 39, 10626.

A. C. McKinlay, R. E. Morris, P. Horcajada, G. Férey, R. Gref, P. Couvreur and C. Serre, Angew. Chemie - Int. Ed.,

S. Zhang, M. M. Melzer, S. N. Sen, N. Çelebi-Ölçüm and T. H. Warren, Nat. Chem., 2016, 8, 663-669.

P. Tavares, A. S. Pereira, J. J. G. Moura and I. Moura, J. Inorg. Biochem., 2006, 100, 2087-2100.

R. V. Pinto and M. L. Pinto, in Therapeutic Application of Nitric Oxide in Cancer and Inflammatory Disorders,

N. J. Hinks, A. C. McKinlay, B. Xiao, P. S. Wheatley and

R. E. Morris, Microporous Mesoporous Mater., 2010, 129,

T. Yang, A. N. Zelikin and R. Chandrawati, Adv. Sci., 2018,

H. C. Zhou, J. R. Long and O. M. Yaghi, Chem. Rev., 2012,

H. Furukawa, K. E. Cordova, M. O'Keeffe and O. M. Yaghi, Science, 2013, 341, 1230444-1230444.

A. C. McKinlay, J. F. Eubank, S. Wuttke, B. Xiao, P. S. Wheatley, P. Bazin, J.-C. Lavalley, M. Daturi, A. Vimont, G. De Weireld, P. Horcajada, C. Serre and R. E. Morris, Chem. Mater., 2013, 25, 1592-1599.

A. Lowe, P. Chittajallu, Q. Gong, J. Li and K. J. Balkus, Microporous Mesoporous Mater., 2013, 181, 17-22.

F. Bonino, S. Chavan, J. G. Vitillo, E. Groppo, G. Agostini, C. Lamberti, P. D. C. Dietzel, C. Prestipino and S. Bordiga, Chem. Mater., 2008, 20, 4957-4968.

E. D. Bloch, W. L. Queen, S. Chavan, P. S. Wheatley, J. M. Zadrozny, R. Morris, C. M. Brown, C. Lamberti, S. Bordiga and J. R. Long, J. Am. Chem. Soc., 2015, 137, 3466-3469. C. K. Brozek, J. T. Miller, S. A. Stoian and M. Dincă, J. Am. Chem. Soc., 2015, 137, 7495-7501.

C. K. Brozek and M. Dincă, J. Am. Chem. Soc., 2013, 135, 12886-12891.
J. Oktawiec, H. Z. H. Jiang, J. G. Vitillo, D. A. Reed, L. E. Darago, B. A. Trump, V. Bernales, H. Li, K. A. Colwell, H. Furukawa, C. M. Brown, L. Gagliardi and J. R. Long, Nat. Commun., 2020, 11, 3087.

A. S. Rosen, M. R. Mian, T. Islamoglu, H. Chen, O. K.

Farha, J. M. Notestein and R. Q. Snurr, J. Am. Chem. Soc., 2020, 142, 4317-4328.

P. Q. Liao, H. Chen, D. D. Zhou, S. Y. Liu, C. T. He, Z. Rui, H. Ji, J. P. Zhang and X. M. Chen, Energy Environ. Sci., 2015, 8, 1011-1016.

X. F. Lu, P. Q. Liao, J. W. Wang, J. X. Wu, X. W. Chen, C. T. He, J. P. Zhang, G. R. Li and X. M. Chen, J. Am. Chem. Soc., 2016, 138, 8336-8339.

Y. Wang, N. Y. Huang, J. Q. Shen, P. Q. Liao, X. M. Chen and J. P. Zhang, J. Am. Chem. Soc., 2018, 140, 38-41.

R. D. Jones, D. A. Summerville and F. Basolo, Chem. Rev., 1979, 79, 139-179.

J. H. Enemark and R. D. Feltham, Coord. Chem. Rev., 1974, 13, 339-406.

T. G. Traylor and V. S. Sharma, Biochemistry, 1992, 31, 2847-2849.

S. S. Batsanov, Inorg. Mater., 2001, 37, 871-885.

K. Nakamoto, J. Fujita and H. Murata, J. Am. Chem. Soc., 1958, 80, 4817-4823.

R. B. Penland, T. J. Lane and J. V. Quagliano, J. Am. Chem. Soc., 1956, 78, 887-889.

R. L. Hudson, M. J. Loeffler and P. A. Gerakines, J. Chem. Phys., 2017, 146, 1-9.

K. Nakamoto, Infrared Raman Spectra Inorg. Coord. Compd., 2009, 1-273.

E. C. Niederhoffer, J. H. Timmons and A. E. Martell, Chem. Rev., 1984, 84, 137-203.

E. G. Abucayon, R. Khade, D. R. Powell, Y. Zhang and G.

B. Richter-Addo, Angew. Chem. Int. Ed., 2019, 2-8.

C. H. Chuang, W. F. Liaw and C. H. Hung, Angew. Chemie - Int. Ed., 2016, 55, 5190-5194.

G. B. Wijeratne, M. Bhadra, M. A. Siegler and K. D. Karlin, J. Am. Chem. Soc., 2019, 141, 17962-17967.

A. Ruyra, A. Yazdi, J. Espín, A. Carné-Sánchez, N. Roher, J. Lorenzo, I. Imaz and D. Maspoch, Chem. - A Eur. J., 2015, 21, 2508-2518.

X. Han, S. Yang and M. Schröder, Nat. Rev. Chem., 2019, 3, 108-118.

J. Jover, C. K. Brozek, M. Dincă and N. López, Chem. Mater., 2019, 31, 8875-8885.

A. Shiotari, S. Hatta, H. Okuyama and T. Aruga, Chem. Sci., 2014, 5, 922-926.

N. Yeung, Y. W. Lin, Y. G. Gao, X. Zhao, B. S. Russell, L. Lei, K. D. Miner, H. Robinson and Y. Lu, Nature, 2009, 462, 1079-1082. S. Matsumoto, K. Yokota, H. Doi, M. Kimura, K. Sekizawa and S. Kasahara, Catal. Today, 1994, 22, 127-146. 